\title{
A ESCOLA NOS DESENHOS DE CRIANÇAS:REPRESENTAÇÕES INFANTIS NO BRASIL E EM PORTUGAL
}

Iraíde Marques de Barreiro Manuela Terrasêca

RESUMO: Esta pesquisa investiga como crianças representam a escola, por meio de desenhos, na transição da Educação Infantil para o $1^{\circ}$ ano do Ensino Fundamental, no Brasil, em uma cidade paulista e do Pré-escolar para o $1^{\circ}$ ciclo do Ensino Básico, em Portugal, Porto. Quais sentidos as crianças atribuem à escola e como percebem suas ações? Este é um estudo com crianças e não sobre crianças. São usadas diferentes metodologias que se articulam, como abordagem qualitativa, educação comparada e análise dos desenhos e usadas duas categorias designadas como informal e formal. O sentimento de pertencimento das crianças portuguesas para com a escola favorece uma visão mais integrada com suas atividades, inclui os funcionários, o entorno da escola e explicita sentimentos, diferentemente das crianças brasileiras.

PALAVRAS-CHAVE: Educação infantil. Ensino fundamental. Representação social. Escola. Desenhos.

\section{INTRODUÇão}

Pensar sobre a escola remete, entre outras questões, à estrutura do sistema escolar, às políticas educacionais, às práticas pedagógicas, aos métodos e aos papéis dos sujeitos escolares. Para estes últimos, os estudantes são vistos mais como partícipes de um grupo de iguais, que poucas vezes são ouvidos e percebidos como singulares.

Esta pesquisa investiga como as crianças representam a escola, por meio de desenhos, no processo de transição da Educação Infantil (EI) para o $1^{\circ}$ ano do Ensino Fundamental (EF) no Brasil e em Portugal, com recorte para uma cidade, em cada país. Representar a escola explicita significados que as crianças atribuem aos fatores sociais que agem sobre o processo educativo e a diferentes situações escolares, nem processo de mão dupla. Ou seja, ao mesmo tempo em que se buscam explicações para as condutas das crianças, os demais interlocutores da escola são mobilizados a rever suas próprias condutas, tendo como parâmetros a formação profissional e as políticas educacionais.

André (2008, p. 142), ao investigar a escola, propõe uma perspectiva teórica que se vale de quatro dimensões interacionadas, "para que se possa apreender o dinamismo próprio da vida escolar". Entre as dimensões propostas pela autora o foco do presente estudo volta-se para a dimensão subjetiva, "que abrange a história de cada sujeito, manifesta no cotidiano escolar, por suas formas concretas de representação social, por meio das quais age, posiciona-se, aliena-se e comunica-se". Para a autora, o estudo da dimensão subjetiva requer contatos com os sujeitos em situações formais e informais que lhes "permitam expressar opiniões, ponto de vistas, concepções e representações" (ANDRÉ, 2008, p. 142). Componente da subjetividade na escola, a cultura escolar exerce grande influência na convivência e na expressão de sentidos atribuídos pela criança e pelo olhar do pesquisador. Nessa direção, Dominique Julia (2001, p. 10) reconhece ser "conveniente compreender também, quando isso é possível, as culturas infantis (no sentido antropológico do termo), que se desenvolvem nos pátios de recreio e o afastamento que representam em relação às culturas familiares".

Com um olhar alargado, esta pesquisa analisa as representações sociais das crianças acerca da escola no processo de transição da Educação Infantil (4 a 5 anos), para o $1^{\circ}$ ano do Ensino Fundamental de nove anos ( 6 anos), por meio de desenhos, coletados no Brasil e em Portugal, cuja Pré-escola é designada de Pré-escolar e o $1^{\circ}$ ciclo do Ensino Básico, equivale ao $1^{\circ}$ ano do 
Ensino Fundamental de nove anos, em nosso país. No Brasil, as escolas participantes estão localizadas em uma cidade do interior paulista e em Portugal, na cidade do Porto.

Em Portugal, as escolas estão organizadas por agrupamentos, conforme Decreto Lei $\mathrm{n}^{\mathrm{o}}$ 115-A/98, de 4 de maio de 1998, decorrente da necessidade de organizar a administração e gestão das escolas portuguesas da educação básica. Os agrupamentos possuem unidades próprias, dotadas de seus órgãos de administração e gestão, desde a educação pré-escolar e demais ciclos, dirigidos por um diretor (coordenador) (PORTUGAL, 1998).

O sistema de ensino português está organizado em: ensino pré-escolar ( 3 a 5 anos); ensino básico: $1^{\circ}$ ciclo (6 a 9 anos); $2^{\circ}$ ciclo (10 e 11 anos); $3^{\circ}$ ciclo (12 a 14 anos); ensino secundário (15 a 18 anos) e educação superior. Em 1986 foi aprovada a Lei no 46/86, de 14 de outubro de 1986 - Lei de Bases do Sistema Educativo (LBSE), que fixou a escolarização em nove anos (PORTUGAL, 1986).

Em 27 de agosto de 2009 foi promulgada a Lei $n^{\circ}$ 85/2009 que estabelece o regime do alargamento da escolaridade obrigatória para 12 anos e gratuidade da educação pré-escolar para crianças de 5 anos de idade, de modo que a escolaridade obrigatória termina com nível secundário (PORTUGAL, 2009).

Em 16 de junho de 2006 foi publicado o Despacho n ${ }^{\circ}$ 12.591, que regulamenta a Escola a Tempo Inteiro e define as Atividades de Enriquecimento Curricular (AEC), nos domínios desportivo, artístico, científico, tecnológico e das tecnologias da informação, por meio das atividades de apoio ao estudo, ensino de inglês, ensino de outras línguas estrangeiras, atividade física e desportiva, ensino de música, entre outras (PORTUGAL, 2006).

No Brasil, a Lei no 9.394 de 20 de dezembro de 1996 - Lei de Diretrizes e Bases da Educação estabelece as diretrizes e bases da educação nacional e prevê a ampliação do EF para nove anos, com início aos 6 anos de idade (BRASIL, 1996). Em janeiro de 2001, a Lei no 10.172 aprovou o Plano Nacional de Educação/PNE (2001-2011) e a ampliação do EF tornou-se uma das metas, passando de oito para nove anos, com matrícula obrigatória aos seis anos, consolidada pela Lei $\mathrm{n}^{\circ}$ 11.274, de 6 de fevereiro de 2006 (BRASIL, 2006). Com esta lei o Brasil assegurou a inclusão das crianças de 6 anos no convívio escolar, com menor exposição e vulnerabilidade e maior qualidade da educação. Para o Ministério da Educação (BRASIL, 2004 p. 17), “[...] não se trata de transferir para as crianças de seis anos os conteúdos e atividades da tradicional primeira série, mas de conceber uma nova estrutura de organização dos conteúdos no Ensino Fundamental de nove anos, considerando o perfil dos alunos".

Em Portugal, o Despacho $n^{\circ} 12.591 / 2006$, de 16/06/2006, regulamenta a escola a tempo inteiro e define as Atividades de Enriquecimento Curricular (AEC), para a educação básica (PORTUGAL, 2006). Neste mesmo ano, no Brasil, a Lei n ${ }^{\circ} 11.274$, de 6/2/2006 ampliou o ensino fundamental para nove anos, mas não de modo integral. Portugal ampliou o ensino fundamental para nove anos acompanhado da educação a tempo inteiro (PORTUGAL, 2006). Tais diferenças podem ser decisivas para o olhar diferenciado acerca da escola, em contextos diferentes, entre as crianças dos dois países.

Esta pesquisa busca adentrar ao universo das crianças, em dois territórios diferentes, para verificar como as crianças veem, sentem e projetam sua escola em seus desenhos, valendo-se do seu imaginário e não a partir de o imaginário do adulto, projetado na criança. Desse modo, as análises e compreensão desses contextos consideram [...] aquilo que é dito e aquilo que não é 
dito, porque se tem crianças de um contexto de 'pouca fala' [...] para compreender o que não é dito ou aquilo que é dito numa 'palavrinha' só, o que é aquilo que sintetiza" (DEMARTINI, 2009, p. 8).

Almeida e Teixeira (2006) também investigam o momento de transição da criança da EI para o EF, face à Lei $\mathrm{n}^{\circ} 11.114$, de 16/5/2005, que tornou obrigatório o início do ensino fundamental aos 6 anos de idade (BRASIL, 2005). A pesquisa busca emergir as vozes das crianças e caracterizar o significado - na perspectiva da criança - do processo de transição da EI para o EF. As autoras elegem "o desenho como forma privilegiada de acesso à representação infantil por considerá-lo uma rica possibilidade da expressão, que permite uma 'leitura' imagética de significativo valor" (ALMEIDA; TEIXEIRA, 2006, p. 5).

Em outro estudo, Nova (2013) analisa as representações sociais de escola das crianças, com base em seus desenhos. A pesquisa se insere na proposta de investigação subjetiva da escola e focaliza as representações sociais de escola, das crianças matriculadas no primeiro ciclo, em 12 instituições escolares municipais, em áreas periféricas de Recife/PE.

A teoria das representações sociais tem como seu grande expoente Serge Mocovici, naturalizado francês, que avançou neste campo de estudo por meio da psicologia. Ao buscar compreender como a produção de conhecimentos constitui e reforça a identidade dos grupos, como influem em suas práticas e como elas constituem o pensamento, muito tem contribuído no campo da educação, para a compreensão de diferentes fenômenos no domínio simbólico.

Para Moscovici (1978), é sempre provisória a forma como o sentido social de um determinado objeto é apropriado pelo sujeito na sua prática concreta, porque tanto o homem quanto os objetos estão em permanente construção. O estudo das representações sociais permite revelar a materialidade histórica, a tensão estabelecida entre sujeito e objeto, articulada na relação indivíduo/sociedade como dimensões concretas não isoladas, marcadas pela dinâmica e pela dialética. Portanto, as representações não se estruturam isoladamente, mas integram e compõem a dinâmica pela qual o real torna-se concreto para o homem, de modo que ao defini-lo também se define, se singulariza. Para Moscovici (1978), a representação possui a função de elaborar comportamentos, condutas e permitir a comunicação.

Para Spink (1995), as representações sociais orientam as ações permeando condutas e diálogos. Significa dizer que são, ao mesmo tempo, formas de conhecimento prático possuidoras de funcionalidade no cotidiano. Este conhecimento é prático porque foi construído por meio de interações sociais no cotidiano das pessoas, com vistas à compreensão e ação sobre a realidade em que vivem. A sua funcionalidade se encontra no fato de que sua existência não está descolada do real. Ao contrário, é fruto da experiência humana e se inscreve em sua práxis cotidiana, participando da construção das subjetividades individual e coletiva.

Logo, a análise dos desenhos possibilita descortinar as múltiplas representações das crianças acerca da escola e ao mesmo tempo explicitar as significações sociais no processo educativo, o que permite (re)significar ações, rever problemas e propor novos encaminhamentos, tendo em vista que as representações sociais das crianças constituem-se em meios, por intermédio dos quais, se estruturam a aprendizagem e suas relações com a escola, na forma como a percebem.

Esta pesquisa investiga como crianças representam a escola, por meio de desenhos, na transição da Educação Infantil para o $1^{\circ}$ ano do Ensino Fundamental, no Brasil, em uma cidade paulista e do Pré-escolar para o $1^{\circ}$ ciclo do Ensino Básico, em Portugal, em uma determinada 
cidade. Como as crianças representam a escola nesses dois níveis de ensino? Quais elementos da escola compõem o imaginário das crianças?

\section{Metodologia e coleta dos desenhos}

Como a investigação abarca realidades próprias em contextos diferentes entre países, a metodologia da pesquisa combina diferentes enfoques para melhor se aproximar da realidade e compreender como as crianças representam a escola, referenciada a um determinado contexto econômico, educacional, histórico e cultural nos dois países. Estes universos influenciam e determinam o olhar das crianças sobre a escola, pois, conforme Dominique Julia (2001, p. 10), a cultura escolar forma-se

[...] como um conjunto de normas que definem conhecimentos a ensinar e condutas a inculcar, e um conjunto de práticas que permitem a transmissão desses conhecimentos e a incorporação desses comportamentos; normas e práticas coordenadas a finalidades que podem variar segundo às épocas (finalidades religiosas, sociopolíticas ou simplesmente socialização). (JULIA, 2001, p. 10).

A cultura escolar e os fatores sociais das duas realidades dos países investigados agem no processo educativo e na forma peculiar das crianças representarem e atribuírem significados à escola.

A pesquisa está fundamentada na abordagem qualitativa, que tem o ambiente natural como sua fonte, os dados e o contato direto do pesquisador com a situação investigada (LÜDKE; ANDRÉ, 1986), aliada à análise da documentação pertinente às duas realidades pesquisadas, bem como aos seus aspectos históricos. Ainda, o olhar comparado mostrou-se importante ao analisar as diferenças nas trajetórias das políticas, tendo em vista as relações culturais e políticas que lhes dão significado histórico, ou seja, considerar a totalidade do estudo (FRANCO, 2000). Problemas comuns a realidades educacionais diferentes podem ser analisados em busca de soluções similares para melhor se refletir acerca de a realidade local.

A pesquisa desenvolveu um estudo com crianças e não sobre crianças. Os desenhos foram escolhidos como instrumentos metodológicos, para adentrar ao imaginário infantil, por serem capazes de expressar e captar as percepções das crianças no processo de atribuição de sentidos e exteriorização do real, sobretudo quando acompanhados das falas ou escritas espontâneas das crianças enquanto produziam os desenhos ou após. "O desenho e a oralidade são compreendidos como reveladores de olhares e concepções dos pequenos e pequenas sobre seu contexto social, histórico e cultural, pensados, vividos e desejados" (GOBBI, 2009, p. 71).

Os desenhos foram coletados no horário normal de aula das crianças, em suas respectivas salas, estando disponíveis lápis preto, de cores e folha de papel A4, por ser de fácil acesso. Foi solicitado às crianças brasileiras e portuguesas matriculadas no $1^{\circ}$ ano do Ensino Fundamental (EF) $/ 1^{\circ}$ ano do ciclo básico, em Portugal, que rememorassem a escola da pré-escola da Educação Infantil (EI)/pré-escolar e a desenhassem; o que lembravam, como era a escola e desenhassem a sua pré-escola. Alguns dias após, a mesma solicitação foi feita, à mesma sala de aula, agora, para desenharem a escola atual, do $1^{\circ}$ ano do EF. Às crianças foi solicitado a desenharem sua escola atual, ou seja, como é a escola do $1^{\circ}$ ano do EF. Tanto ao desenharem a pré-escola quanto a escola atual, antes de recolher os desenhos, cada criança foi perguntada, individualmente, o que havia desenhado e foi anotado no próprio desenho. A maioria das crianças portuguesas, quando 
perguntadas, já havia nomeado e escrito o que elas haviam desenhado. Por iniciativa própria nomearam objetos e diferentes situações nas quais se incluíam. Já entre as crianças brasileiras apenas algumas escreveram seus nomes e alguns números.

No Brasil, a coleta dos desenhos na EI foi realizada ao final do ano e a do $1^{\circ}$ ano do EF no segundo semestre do ano seguinte, para que as crianças pudessem vivenciar por mais tempo a escola no $1^{\circ}$ ano do EF e ter elementos para representá-la. Tal situação permitiu, na maioria das vezes, analisar desenhos de uma mesma criança nos dois níveis de ensino - EI e EF. As escolas pesquisadas nos dois países estão localizadas mais próximas da periferia, o que em tese, seriam similares.

Em Portugal, como o ano letivo se inicia no segundo semestre e, portanto as crianças matriculadas no $1^{\circ}$ ano do EF também haviam frequentado a escola por seis meses, quando participaram da pesquisa. Logo, foi possível analisar os desenhos de uma mesma criança nos dois ciclos, EI e $1^{\circ}$ ano do EF.

Os desenhos das crianças brasileiras e portuguesas foram divididos em duas grandes categorias, denominadas: espaço informal (EI) e espaço formal ( $1^{\circ}$ ano do EF). Nem sempre estes espaços são representados distintamente, na EI e no EF, assim como o aprender não prescinde do brincar. Por meio destas categorias foi verificado em que medida as atividades lúdicas são percebidas nos dois níveis de ensino.

No Brasil a coleta dos desenhos ocorreu em duas salas de aula do $1^{\circ}$ ano do EF, com 20 alunos em cada sala, nas quais as crianças rememoram a escola de EI e do EF, com um intervalo de tempo, em duas escolas diferentes. Em Portugal os procedimentos foram os mesmos, sendo que uma sala de aula tinha 17 alunos e a outra 16. Os desenhos foram analisados individualmente de acordo com duas categorias designadas como espaço informal, composto pelas atividades lúdicas (jogar, desenhar, ouvir histórias, jogos, casa de bonecas, correr no pátio, pista de correr, recreio, televisão, esconde-esconde, balanço, cantina, recreio, animais, escorregador, dentre outras). Espaço formal, pelas atividades na sala de aula e na escola (quadro negro, carteiras, escrever o nome, quadro silábico, calendário, leitura, biblioteca computador, fazer trabalhos, entre outras).

As análises dos desenhos das crianças brasileiras e portuguesas indicam grandes diferenças nas formas como representam a escola. No caso das primeiras, em ambos os ciclos, a escola é representada como mais estática e praticamente as crianças não desenham a ocorrência de atividades na sala de aula ou no pátio. De modo contrário, as crianças portuguesas apresentam a escola de modo dinâmico, com mais vida, rica em atividades, com grande familiaridade com as letras e números, além de expressarem mais seus afetos em relação ao que se aprende e às pessoas.

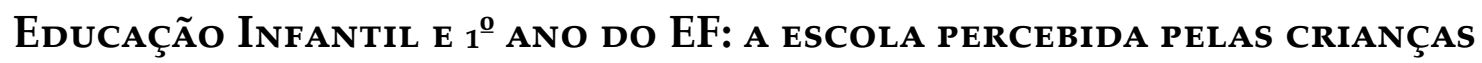 BRASILEIRAS}

As crianças nem sempre representam a EI e o $1^{\circ}$ ano do EF distintamente, em dois momentos ou em dois espaços. Há crianças que organizam as duas situações em um único desenho, com atividades lúdicas nas duas situações. Isso pode ser indicativo de que esta passagem não é sentida como estanque para as crianças, como é percebida pelos adultos, ou que fazem um bom processo de elaboração nesta passagem. Ou ainda, mesmo expressando as modificações do $1^{\circ}$ ano do EF, as crianças incorporam a quadra, a bola, o balanço neste espaço, diferente da forma 
como a maioria dos adultos vê a escola pelo crivo do certo/errado, adequado/inadequado, em que o lúdico não compõe a aprendizagem.

As falas e nomeações das crianças acerca de seus desenhos foram importantes por possibilitar melhor compreensão dos sentidos e significados atribuídos à escola pelas crianças, permitindo "dirigir o olhar e dialogar com os desenhos e seus produtores" (GOBBI, 2009, p. 83).

Nos desenhos da criança A, ela representa os espaços informal e formal, da EI e do $1^{\circ}$ ano do EF. As duas situações ocupam a página inteira, indicativas de maior segurança da criança. Porém é nítida a pressão maior do lápis ao desenhar sua escola da EI (Figura 1), indicativa de maior vontade e entusiasmo, com maior vivacidade das cores, espaço bem preenchido, uso de cores fortes e um coração pintado em vermelho. Na parte baixa do desenho há crianças alegres brincando, entre as quais se incluiu também. Retrata uma escola alegre e vivaz. Quando comparada à Figura 2, na qual se autorretratou, conforme disse, no $1^{\circ}$ ano do EF com as coleguinhas, sentada em carteiras enfileiradas, estudando, é possível notar que o desenho não está tão bem finalizado quanto ao da EI. As crianças sentadas nas carteiras são minúsculas e a porta da sala está fechada. A forma $\mathrm{O}$ acabamento deste desenho, quando comparado como o da pré-escola sugere certa impaciência na conclusão, bem como sua preferência pela escola da educação infantil. Os dois desenhos retratam uma separação nítida em relação aos espaços informal e formal, em que o primeiro expressa a ludicidade e o segundo o trabalho, com carteiras enfileiradas e porta fechada.

A inadequação do mobiliário (carteiras muito altas na Figura 2) e a organização do espaço escolar indicam a desproporção do tamanho das crianças em relação aos móveis e a separação rígida entre os dois níveis de ensino. No início da implantação do ensino fundamental de nove anos, algumas escolas brasileiras mantiveram a mesma estrutura física e espacial de sala de aula e adquiriram móveis diferenciados adequados às crianças de 6 anos, mais tardiamente.

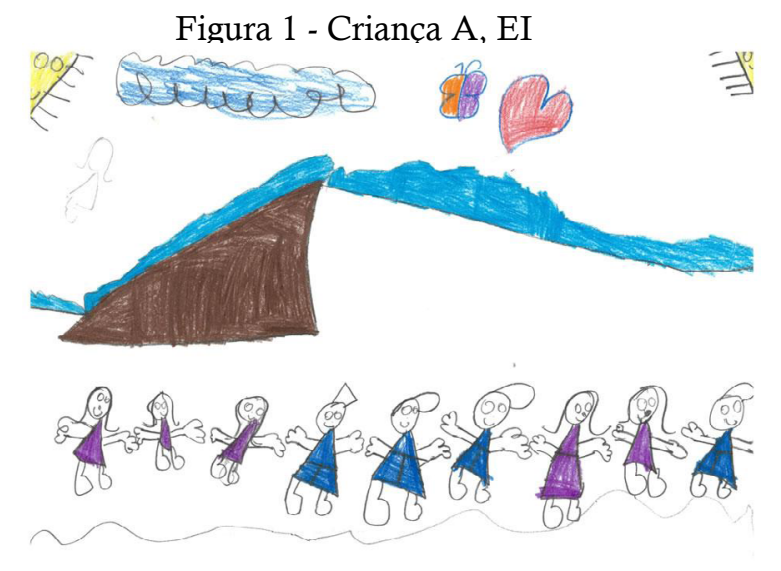

Fonte: Arquivo da pesquisadora.
Figura 2 - Criança A, $1^{\circ}$ ano do EF

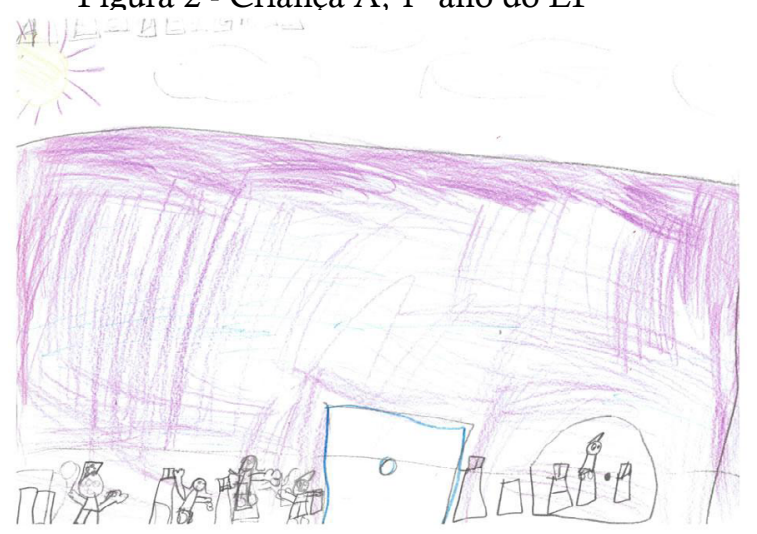

Fonte: Arquivo da pesquisadora.

A mudança da disposição do mobiliário e do espaço da sala deveriam ser acompanhada de mudanças de atitudes dos professores em relação ao aluno e ao processo pedagógico, como bem coloca Julia (2001, p. 11)

Normas e práticas não podem ser analisadas sem se levar em conta o corpo profissional dos agentes que são chamados a obedecer a essas ordens e, portanto, a utilizar disposi- 
tivos pedagógicos encarregados de facilitar sua aplicação, a saber, os professores primários e os demais professores.

Abaixo, dois desenhos de outra criança apresentam características similares em relação à coloração mais fraca, alegres e com poucos elementos diferenciando as duas escolas. Há elementos mais coloridos no desenho da Figura 3, como corações, flor, crianças brincando e a árvore mais frondosa e "aberta". Os espaços foram preenchidos mais cuidadosamente e a criança autorretratou-se "brincando com as amigas na escola". Na Figura 4, a aluna disse: "Estou aqui na escola estudando e o sinal está tocando". A escola, de cor cinza, tem carteira. O sino, destacado na parte alta da parede da escola, indicativo da obediência a um tempo mais rígido e controlado, mesmo com partituras musicais e sol de cara alegre.

Figura 3 - Criança C, EI
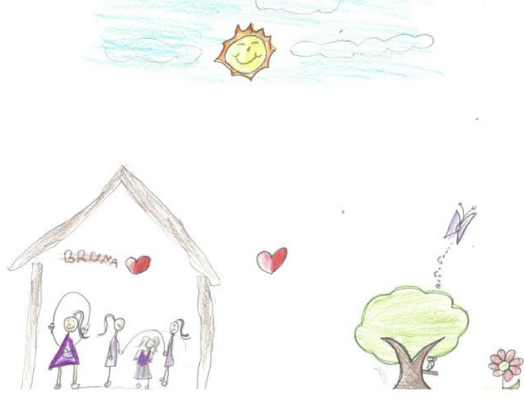

Fonte: Arquivo da pesquisadora.
Figura 4 - Criança $\mathrm{C}, 1^{\circ}$ ano do EF

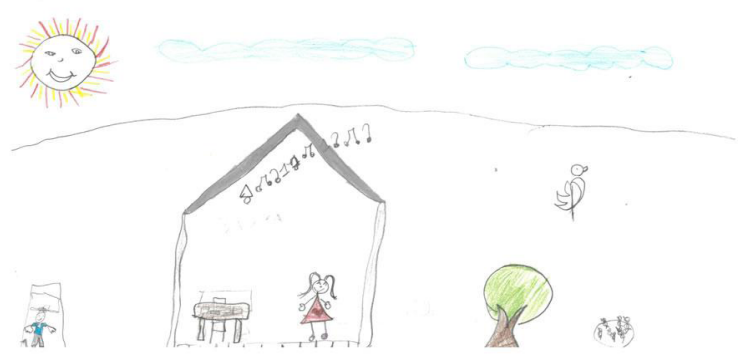

Fonte: Arquivo da pesquisadora.

Considerando os desenhos como documentos que permitem saber mais acerca dessas crianças e conhecer melhor suas percepções da realidade (GOBBI, 2009), o sino tocando explicita a forma como elas têm percebido e sentido o tempo mais rígido, as normas e a organização do espaço formal na sala do primeiro ano.

De modo contrastante, o espaço formal (Figura 6) a criança iniciou o desenho da escola com lápis preto, porta fechada, sem crianças, sem parques e sem brincadeiras. Os "rabiscos" sobre a escola de ensino fundamental não indicam inabilidade motora da criança, diante do traçado firme e forte ao representar a escola na pré-escola (Figura 5). Revelam, talvez, insatisfação da criança e pouca familiaridade com o $1^{\circ}$ ano do EF. Pode-se dizer que houve negação da escola que "ensina", ao estar de portas fechadas e coberta de rabiscos.

Figura 5 - Criança F, EI

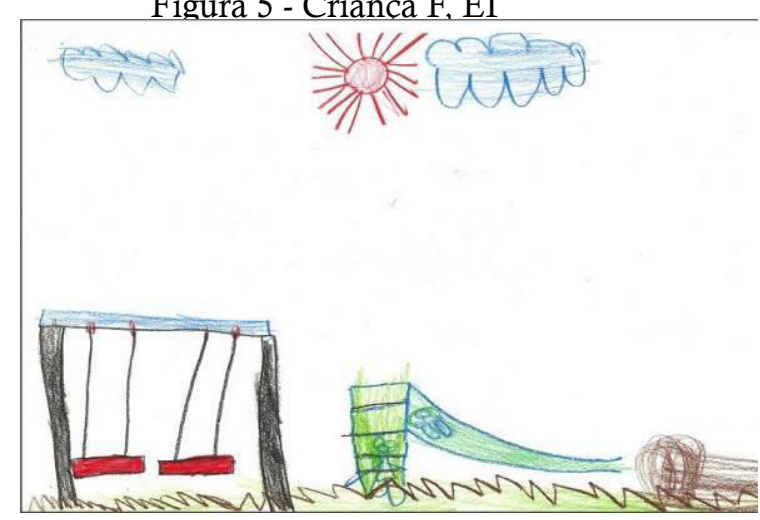

Fonte: Arquivo da pesquisadora.
Figura 6 - Criança $F, 1^{\circ}$ ano do EF

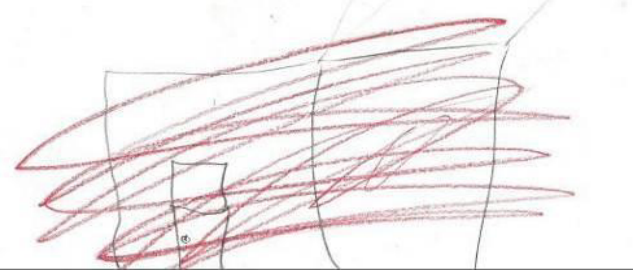

Fonte: Arquivo da pesquisadora. 
Tais peculiaridades estão relacionadas com as formas como as crianças percebem os dois níveis da escolaridade cindidos, como se na pré-escola não houvesse aprendizado de modo mais sistematizado e no ano seguinte, o lúdico, as atividades prazerosas não pudessem mais compor o $1^{\circ}$ ano. Para Gobbi (2009), o desenho traz informações que vão além dele mesmo, extrapolando o registro fiel da realidade, sendo um portador de vínculos construídos entre seus produtores e aqueles em seu entorno.

Os desenhos analisados e apresentados aqui refletem o conjunto dos desenhos coletados nas salas de aula, nos dois níveis de ensino. No geral os desenhos das crianças brasileiras apresentam menos elementos que expressem as atividades pedagógicas, curriculares e até mesmo atividades lúdicas no espaço da sala de aula e externo à escola. Alguns desenhos priorizam a divisão mais radical entre os espaços informal e formal e outros mesclam estes espaços com atividades lúdicas e outras mais formais, "de gente grande". Nossas crianças se restringem mais a desenhar a sala de aula, com carteiras e algumas letras, sem mediação com espaços externos de aprendizagens. São raras as crianças que escrevem seu nome, mesmo estando no $1^{\circ}$ ano do EF. No pátio da escola, desenham o parque, balanços, e não incorporam professores, diretoras e funcionários no conjunto da escola. É um olhar recortado. Também não há nenhum desenho que retrate o entorno da escola. Talvez porque as crianças fiquem a maior parte do tempo na sala de aula, sendo estes níveis de ensino em período parcial e não integral o que, possivelmente, dificulta um olhar mais alargado da escola, ou explicita a pouca valoração na educação básica, para atividades extrassala de aula. Situação muito diferente entre as crianças portuguesas que expressam os dois ciclos da educação - Pré-escolar e $1^{\circ}$ ano do Ciclo Básico -, com dinâmica escolar mais viva, dizem o que gostam de fazer e incorporam os demais profissionais da escola em seus desenhos.

\section{EducaÇão Infantil E $1^{0}$ ANO do EF: A escola PERCEbida PELAS CRIANÇAS PORTUGUESAS}

Assim como ocorreu com os desenhos das crianças brasileiras, em Portugal, essas produções também foram coletadas em duas classes do $1^{\circ}$ ano do EF, de modo que as crianças representaram a escola em dois momentos: na EI e no $1^{\circ}$ ano do EF. Logo, os desenhos de uma mesma criança foram analisados nos dois níveis de ensino, a exemplo dos desenhos das crianças brasileiras. Com isso é possível preservar semelhanças e diferenças na coleta e análises dos desenhos nos dois países, tendo em vista a cultura escolar que os aproxima, mas que também os diferencia. Pois, como afirma Julia (2001), a cultura escolar é um conjunto de normas que definem conhecimentos a ensinar, condutas a inculcar, por meio de práticas escolares.

Importante estudo de Manuela Malpique (1995), intitulado Pequenas histórias: a geografia das crianças - práticas e representaçooes de lugares do dia-a-dia de crianças portuguesas em idade escolar, contribuiu para melhor compreensão e análise dos desenhos das crianças portuguesas. A autora pesquisou a rotina de crianças portuguesas, investigando o trajeto escolar que fazem, por meio de desenhos, por entender que o conjunto de elementos ali presentes possibilita interações sociais que desenvolvem conhecimentos.

Interessa aqui, sobremaneira, a forma como Malpique (1995) analisou os desenhos das crianças, ao destacar os elementos (o que de fato as crianças desenham) mais frequentes nos desenhos das crianças a caminho da escola. Nos desenhos coletados e analisados por Malpique 
(1995), há muitas semelhanças entre os desenhos das crianças portuguesas realizados, para a presente pesquisa, como a arquitetura do telhado das casas e da escola com maior número de janelas (diferentes dos desenhos das crianças brasileiras, em virtude das culturas diferentes), a presença de rampas no espaço externo aos muros da escola, presentes em dois desenhos a seguir, ao representar sua escola de EI.

Os dois desenhos abaixo, realizados pela mesma criança, representam suas percepções acerca da escola em dois momentos distintos de sua escolaridade. Ambos ocupam a página inteira, o que pode indicar maior segurança desta criança, assim como a pressão do lápis ao desenhar é indicativa de maior firmeza e entusiasmo. Porém as atividades lúdicas se fazem mais presentes na Figura 7, com a casa de bonecas, pista de brincar, correr no pátio, recreio, televisão, cantina e menina desenhada alegre e em tamanho maior. O segundo desenho (Figura 8), mesmo contendo poucos elementos da sala de aula, explicita o tanto que a criança gosta do que faz. Ela própria nomeou o que estava fazendo e suas preferências: "gosto do recreio", "gosto de comer", "gosto de aprender letras novas" e "gosto da professora".

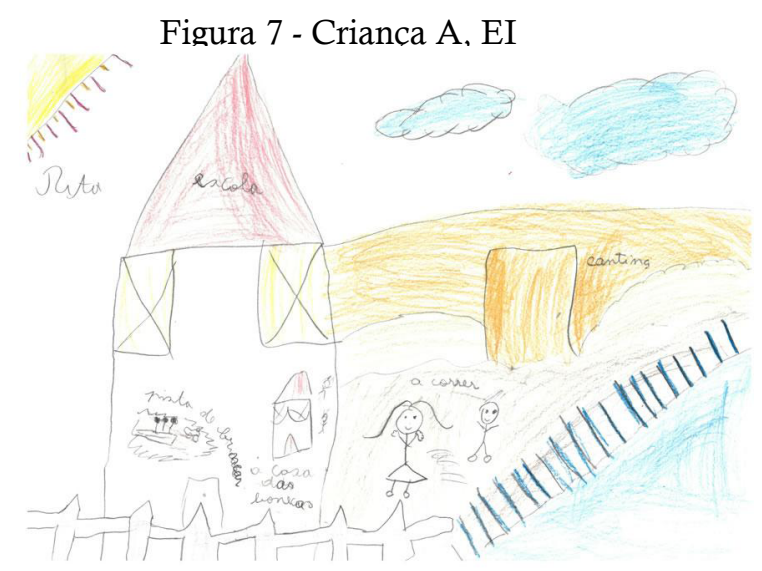

Fonte: Arquivo da pesquisadora.

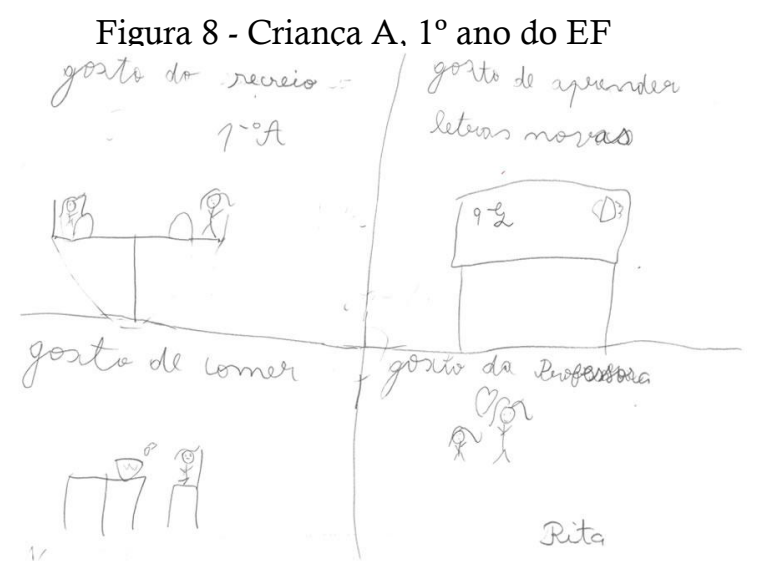

Fonte: Arquivo da pesquisadora.

Mesmo com lápis de cor à disposição, nas duas situações, a aluna optou por representar a escola do $1^{\circ}$ ano do EF somente com lápis preto, autorretratou-se em tamanho menor e listou somente o recreio como momento de lazer presente no ciclo pré-escolar, mantendo diferenciação maior entre os dois níveis de ensino. Nos dois países a EI, quando comparada ao EF, proporciona mais momentos interativos e maior tempo para o brincar, e as brincadeiras no EF estão designadas apenas para o recreio, como percebeu a aluna que produziu os desenhos das Figuras 7 e 8.

No desenho da Figura 9, a criança representa a pré-escola em cores claras, telhado em cone, refere-se ao recreio e está a pintar um desenho com mais colegas em torno de uma mesa quadrada. Desenha a televisão, o pátio com a cantina e o entorno da escola, com rampas, grades e cercas. Trouxe vários elementos relacionados à educação pré-escolar, inclusive a mesa de estudos, como é chamada na sala de aula. Seu desenho, no $1^{\circ}$ ano do EF, apresenta a escola com o mesmo estilo do telhado em cone, a porta fechada em perspectiva, alunos e alunas na sala se aula. Escreve as cinco vogais (a, e, i, o, u) e três contas de adição, marcando muito bem a diferença entre os dois níveis de ensino; entre a escola mais descontraída que brinca e pinta e a escola com atividades mais dirigidas na maior parte do tempo. Chama a atenção o fato de as crianças portuguesas escreverem o seu nome nos desenhos, nomearem atividades e expressarem sentimentos. 
Figura 9 - Criança B, EI

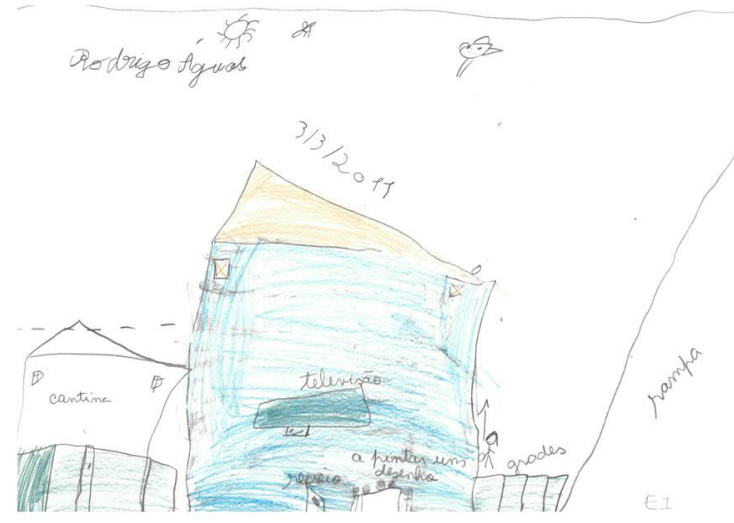

Fonte: Arquivo da pesquisadora.
Figura 10 - Criança $\mathrm{B}$, do $1^{\circ}$ ano do EF

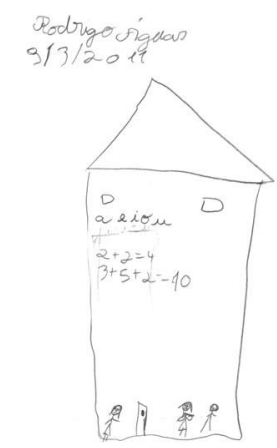

Fonte: Arquivo da pesquisadora.

Para se chegar à escola onde o aluno estuda é preciso subir uma rampa bem íngreme. Para Malpique (1995, p. 339), "O conteúdo do bairro é vivenciado, percepcionado, desenhado ou recusado e quase exclusivamente funcional ou lúdico. O peso dos estereótipos do meio ambiente é muito importante na formação da imagem do bairro nas crianças". A valorização do entorno da escola pelas crianças portuguesas pode ser um indicativo do enaltecimento de outras práticas culturais apreciadas pela escola, que vão além da sala de aula. Em Portugal é valorizado e cultivado visitas a museus, concertos, ao próprio bairro, como parte integrante da educação. No Brasil, o foco de aprendizagem é centrado na escola, tendo a sala de aula como locus possibilitador da produção de conhecimentos e de aprendizagens.

Diferentemente dos desenhos expressos nas Figuras 9 e 10, os desenhos apresentados nas Figuras 11 e 12 integraram de modo harmônico atividades dos dois níveis de ensino, mostrando as escolas da EI e do $1^{\circ}$ ano do EF, mesmo que não tenha desenhado a estrutura física de sua escola. A criança desenhou em branco e preto, por sua opção, e escreveu seu nome completo; sua ilustração ocupou a página toda com traçado forte e seguro, o que pode denotar que ele os fez com firmeza e detalhamento. Seus desenhos são, de fato, ricos em detalhes. Ao representar a escola quando era aluno da EI, coloca-se como partícipe em diferentes atividades lúdicas, como: dormir, jogar bola, fazer ginástica, dançar, partir uma tábua, desenha um vestido de carnaval e a televisão. Desenha atividades da sala de aula (fazendo os trabalhos, desenhos e sentado na carteira escolar ao lado de outra criança). Merece destaque a explicitação de seus afetos, "gosto dos amigos" e os desenha; "gosto da professora" e a desenha duas vezes; sozinha e na margem direita com ele, "eu a dar beijinhos à professora", além de escrever o que estava fazendo.

Figura 11 - Criança C, EI

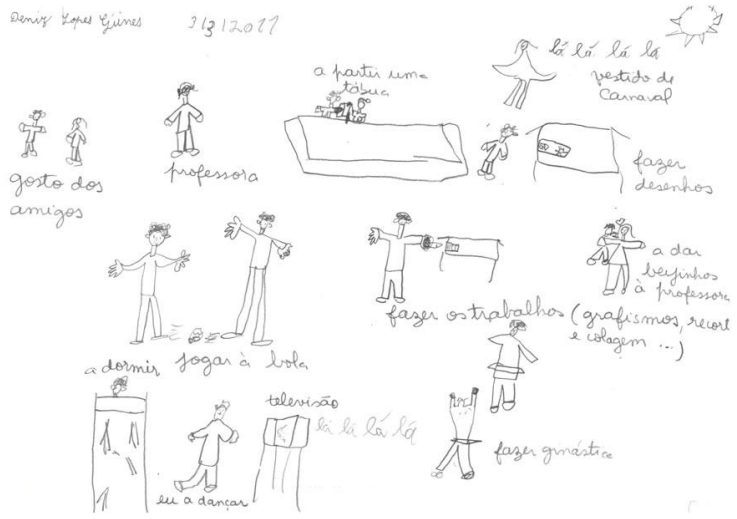

Fonte: Arquivo da pesquisadora.
Figura 12 - Criança $\mathrm{C}$, do $1^{\circ}$ ano do EF

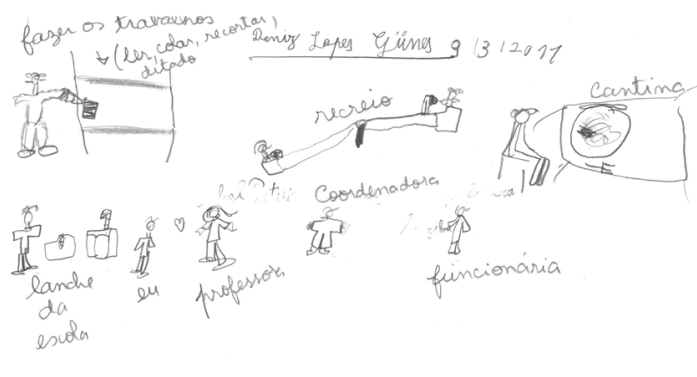

Fonte: Arquivo da pesquisadora. 
Ao desenhar sua escola atual ( $1^{\circ}$ ano), a criança mantém o mesmo estilo gráfico do primeiro desenho, com pessoas em tamanho menor, o que pode indicar que não estivesse tão à vontade na "escola de gente grande" (como as professoras dizem), ao estimularem os alunos para as atividades. Ele desenha atividades lúdicas, como recreio, cantina e lanche da escola; e atividades de aula, como ler, colar, recortar, ditado. Chama a atenção que, além de fazer seu autodesenho, inclui a professora, a coordenadora (diretora da escola) e uma funcionária, o que expressa uma percepção ampliada do que seja a escola, que não se restringe somente à sala de aula. Novamente, a exemplo da representação da EI, explicita seu afeto à professora, ao desenhar um coração entre ambos.

Este olhar mais alargado acerca da escola, com a representação e nomeação de atividades desenvolvidas na escola, a inclusão da diretora e funcionários não foram encontrados nos desenhos das crianças brasileiras. A hipótese é que, no Brasil, pelo fato de a sala de aula constituir-se no espaço privilegiado, senão o único, para o ensino e a aprendizagem, também cerceia as crianças de uma visão mais ampla do que seja escola. Afora ainda, em Portugal, como já mencionado, tanto na EI, quanto no EF, para todos os anos, é ofertada a escola a tempo inteiro (integral), opcional no Brasil, ou ainda com oferta restrita a determinadas escolas. Nas escolas portuguesas pesquisadas, a própria rotina escolar favorece maior integração e sensação de pertencimento das crianças, desde o lanche, almoço, recreios matutinos e vespertinos, lanche da tarde, momentos de convivência coletiva, intercalados com as atividades didático-pedagógicas, até o final do dia.

Em 2006, por meio do Despacho no 12.591, definiram-se as Atividades de Enriquecimento Curricular (AECs) que compõem a escola a tempo inteiro, como: atividade de apoio ao estudo, ensino de inglês, ensino de outras línguas estrangeiras, atividade física e desportiva, ensino de música, outras expressões artísticas de acordo com as necessidades das escolas (PORTUGAL, 2006). Certamente tais atividades integram melhor o lúdico e o aprender, o informal/formal, atribuindo maior significância de sentido à escola, para as crianças, como espaço formador integral. Com isso elas explicitam sentimentos de prazer (gostar de), integração, desenhos mais ricos em detalhes, com rotinas dinâmicas, decorrentes de suas vivências educacionais.

A maioria das AECs é desenvolvida em sala de aula, por profissionais diferentes dos docentes da classe. Mas existe o caráter de estudo, de trabalho e não de oficinas opcionais para ocupar o tempo. As atividades física e desportiva ocorrem no pátio, em quadra fechada ou em sala equipada, sob orientação do instrutor, momento do qual as crianças mais gostam, assim como as crianças brasileiras gostam da educação física.

Para Malpique (1995, p. 524), os jogos no pátio permitem às crianças se apropriarem dos espaços da escola, ao lançarem outro olhar para a escola "[...] é dada às crianças a possibilidade de uma apropriação imaginária dos lugares da escola", que cabe acrescentar, neste caso, independe da nacionalidade. Tais colocações reforçam a tese de que a incorporação do lúdico e do brincar na educação é tarefa difícil, mas é preciso que seja investido pelos executores de políticas, formadores de professores e pelos docentes na sala de aula. Constitui-se em desafio a construção de uma nova cultura escolar, na qual o aprender e o prazer deveriam caminhar juntos. Talvez, quando as crianças combinem parquinho, balanço e ensino fundamental também queiram nos dizer, que é possível uma escola na qual o prazer pela descoberta possa perpassar todas as dimensões e níveis da educação escolar, favorecedora de uma educação mais humanizada. 


\section{CONCLUSÕes}

No Brasil, em 2006, as escolas passaram a receber as crianças de 6 anos para o primeiro ano do ensino fundamental de 9 anos e foram adaptando seus espaços e demandas às condições da nova política. Em Portugal, mesmo com algumas restrições ao funcionamento da política da educação a tempo inteiro, professores e coordenadores reconhecem a importância desta educação. O Despacho $\mathrm{n}^{\circ}$ 12.591/2006 definiu normas para o funcionamento e a oferta das Atividades de Enriquecimento Curricular (AECs) que compõem a educação a tempo inteiro, como oferta obrigatória (PORTUGAL, 2006). No Brasil, ampliou-se o EF para 9 anos, mas não de modo integral, sendo opcional para os municípios e estados (BRASIL, 2006).

A educação portuguesa a tempo inteiro, desde a EI, certamente contribui para uma formação mais integral e uma percepção mais ampliada das crianças acerca dos diferentes sentidos formadores da escola em suas vidas. Desse modo, o processo de passagem da EI para $1^{\circ}$ ano do EF não representa uma grande cisão entre a "escola que brinca" e a "escola que aprende", mas tão somente uma passagem para a "escola de gente grande", como é dito em Portugal. Não só não representa uma cisão, como representa um processo de transição para outra etapa da vida das crianças e de aquisição de novos conhecimentos e saberes. Essa transição se faz presente no conjunto dos desenhos das crianças portuguesas, que ao representarem a escola de EF o fazem incorporando elementos da pré-escola, como parque, jogos e recreio, mas valorizam as novas atividades pedagógicas, como o gosto por "estar a trabalhar".

Ao se refletir sobre os dois grandes conjuntos de desenhos das crianças brasileiras e portuguesas, algumas questões chamam a atenção. Entre as crianças portuguesas os desenhos transcendem a escola e vão até o seu entorno, ao desenhar, por exemplo, a rampa (rua íngreme) de acesso à escola, a cerca da escola e as grades. Há explicitação clara de afetividade por parte de crianças, como "gosto da professora", "gosto de meus colegas", bem como manifestações positivas em relação às atividades de que mais gostam: "gosto de ler", de "aprender letras novas", "de ouvir histórias".

Esta percepção ampliada e o sentimento de pertencimento das crianças em relação à escola as levam a uma visão mais integrada da escola como formadora, expressada por meio das atividades desenvolvidas e com a inclusão dos funcionários, da educadora (que desenvolve as atividades extracurriculares), da coordenadora (diretora da escola) e consequentemente, maior integração entre os diferentes momentos e elementos das atividades proporcionados pela escola, que aliam o brincar e a aprendizagem - tudo é escola. Tal percepção deve-se, ainda, à forma como as Atividades de Enriquecimento Curricular são desenvolvidas. Complementam o tempo integral da escolaridade das crianças, de modo mais integrado e prazeroso.

Do lado brasileiro, a maioria das crianças, em seus desenhos, se atém mais à representação das carteiras da sala de aula e ao desenho de algumas letras, sem mencionar outras atividades desenvolvidas na sala de aula ou na escola, como contato com números, leituras, contar histórias, aprender letras, escrever o próprio nome, como fizeram as crianças portuguesas. Para as crianças brasileiras, o entorno da escola vai até o parquinho, não há demonstração explícita (por meio de palavras e escrita) de afetos, assim como não aparece nos desenhos os demais profissionais da escola além de si próprios, da professora e dos colegas. A representação da escola da EI e do EF apresentam elementos quase sempre equânimes, não expressando grandes diferenças entre as duas escolas que, por outro lado, revela e ou reforça dinâmicas mais carentes, com me- 
nos conhecimentos e menos interações entre as crianças e as atividades pedagógicas e de lazer. Pouco aparece a escrita de letras e números em seus desenhos ao contrário do que ocorre entre as crianças portuguesas.

Uma questão comum aos desenhos das crianças brasileiras e portuguesas é a expressão da organização espacial e serial da sala de aula, ao representarem os dois níveis de ensino nos desenhos e outros indicativos disciplinares, como presença de sinos, grades, câmeras e cercas. Como afirma Foucault (1983, p. 130), "a disciplina procede em primeiro lugar à distribuição dos indivíduos no espaço".

Por fim, como parte integrante deste Dossiê que procura colocar em questão as políticas educacionais e a formação humana, destaca-se a importância de que a educação brasileira deva ressignificar o lúdico no contexto educacional de formação das crianças da EI e no EF, bem como na formação de professores para estes níveis de ensino. Negar o universo simbólico do lúdico, sob o argumento de que esse não é o papel da instituição escolar, é negar o trajeto do desenvolvimento e da aprendizagem das crianças. Os desenhos das crianças brasileiras explicitam esta carência, quando comparados aos das crianças portuguesas. O desafio está posto e cabe aos formadores de professores romperem com visões estanques de educação. Uma escola voltada para a humanização, para além da instrução, requer a superação de exclusões e de distorções históricas que têm marcado nosso olhar e práticas no cotidiano escolar.

\title{
THE SCHOOL IN CHILDREN'S DRAWINGS: CHILDREN'S REPRESENTATIONS IN BRAZIL AND PORTUGAL
}

\begin{abstract}
This research investigates how children represent their school, by means of drawings, in their transition from early childhood education to the $1^{\text {st }}$ grade of grade high school in a town in São Paulo State, Brazil, and from preschool education to the $1^{\text {st }}$ basic cycle in Porto, Portugal. Which meanings are assigned to school and how do they perceive their actions? This is a study with children and not about children. Different articulating methodologies are used, as a qualitative approach, compared education and drawing analysis, made by informal and formal categories. Portuguese children's sense of belongingness to school favors a more integrated view with their activities, includes school officials, its surroundings and explains their feelings, unlike Brazil.
\end{abstract}

KEYWORDS: Early childhood education. Grade/junior high school. Social representation. School. Drawings.

\section{REFERÊNCIAS}

ALMEIDA, A. J. F. de; TEIXEIRA, T. C. F. A escola de nove anos e a dimensão lúdica da natureza infantil. (GEAL-FEUSP). Disponível em: <http://alb.com.br/arquivo-morto/edicoes anteriores/ anais16/sem10pdf/sm10ss14 01.pdf > . Acesso em: 17 ago. 2019. Faculdade de Educação da USP. 2006 ANDRÉ, M. E. D. A. Pesquisas sobre a escola e pesquisas no cotidiano da escola. In: Eccos, Revista Científica, São Paulo, vol. 10, nº. especial, p. 133-145, 2008.

BRASIL. Presidência da República. Casa Civil. Subchefia para assuntos jurídicos. Lei $\mathrm{n}^{\circ} 11.274$, de 6 de fevereiro de 2006. Altera a redação dos arts. 29, 30, 3287 da Lei n ${ }^{\circ}$ 9.394, de 20 de dezembro de 1996, que estabelece as diretrizes e bases da educação nacional, dispondo sobre a duração de 9 (nove) anos para o ensino fundamental, com matrícula obrigatória a partir dos 6 (seis) anos de idade. Disponível em: <http://www.planalto.gov.br/ccivil 03/ Ato2004-2006/2006/Lei/111274.htm>. Acesso em: 02 mar. 2018.

BRASIL. Presidência da República. Casa Civil. Subchefia para assuntos jurídicos. Lei $\mathrm{n}^{\circ} 11.114$, de 16 de maio de 2005. Altera os arts. $6^{\circ}, 30,32$ e 87 da Lei n ${ }^{\circ} 9.394$, de 20 de dezembro de 1996, com o objetivo 
de tornar obrigatório o início do ensino fundamental aos seis anos de idade. Disponível em: <http:// www.planalto.gov.br/ccivil 03/Ato2004-2006/2005/Lei/L11114.htm>. Acesso em: 09 fev. 2017.

BRASIL. Lei no 9.394, de 20 de dezembro de 1996. Estabelece as Diretrizes e Bases da Educação Nacional. Diário Oficial da União, Brasília, DF, v. 134, n. 248, 23 dez. 1996, seção 1, p. 27834-27841.

BRASIL. Ministério da Educação e do Desporto. Secretaria de Educação Básica. Ensino Fundamental de Nove Anos - orientações gerais. Brasília: MEC/SEB, 2004. Disponível em: < http://portal.mec.gov. br/seb/arquivos/pdf/9anosgeral.pdf >. Acesso em: 09 fev. 2018.

BRASIL. Presidência da República. Casa Civil. Subchefia para assuntos jurídicos. Lei ${ }^{\circ} 10.172$, de 09 de janeiro de 2001. Aprova o Plano Nacional de Educação e dá outras providências. Disponível em: $<$ http://www.planalto.gov.br/ccivil 03/leis/leis 2001/110172.htm>. Acesso em: 17 ago. 2018.

DEMARTINE, Z. de B. F. Infância, pesquisa e relatos orais. In: GOULART, A. L. de; DEMARTINE, Z. de B. F.; PRADO, P. D. (Org.). Por uma cultura da infância: metodologias de pesquisa com crianças. 3. ed. Campinas: Autores Associados, 2009. p. 1-20.

FOUCAULT, M. Vigiar e punir: nascimento da prisão. 2. ed. Tradução de Lígia M. Pondé Vassalo. Petrópolis: Vozes, 1983.

FRANCO, M. C. Quando nós somos o outro: questões teórico-metodológicas sobre os estudos comparados. In: Educação \& Sociedade, Campinas, v. 21, nº. 72, p. 197-230, ago. 2000.

GOBBI, M. Desenho Infantil e Oralidade: instrumentos para pesquisa com crianças pequenas. In: GOULART, A. de; DEMARTINE, Z. de B. F.; PRADO, P. D. (Orgs.). Por uma cultura da infância: metodologias de pesquisa com crianças. 3. ed. Campinas: Autores Associados, 2009. p. 69-92.

JULIA, D. A cultura escolar como objeto histórico. Tradução de Gizele de Souza. Revista Brasileira de História da Educação, Campinas, nº. 1, p. 9-43, jan./jun. 2001.

LÜDKE, M.; ANDRÉ, M. D. A. Pesquisa em educação: abordagens qualitativas. São Paulo: EPU, 1986. MALPIQUE, M. B. S. Pequenas histórias: a geografia das crianças-práticas e representações de lugares do dia-a-dia de crianças portuguesas em idade escolar. 1995. 669 f. Tese de Doutorado, Programa de Pós Graduação em Psicologia, da Faculdade de Psicologia e de Ciências da Educação, Universidade do Porto, Portugal, vol. 2, 1995.

MOSCOVICI, S. A representação social da psicanálise. Rio de Janeiro: Zahar, 1978.

NOVA, T. de B. B. Representações sociais de escola das crianças: uma análise a partir de seus desenhos. In: Reunião Anual da Associação Nacional de Pesquisa e Pós-Graduação - Anped, 36., 2013, Goiânia. Anais... Goiânia: ANPED, 2013. p. 1-20. Disponível em: < http://www.anped.org.br/sites/default/ files/gt20 3012 texto.pdf>. Acesso em: 02 mar. 2018.

PORTUGAL. Decreto Lei $\mathrm{n}^{\circ} 115-\mathrm{A} / 98$, de 04 de maio de 1998. Aprova o regime de autonomia, administração e gestão dos estabelecimentos públicos da educação pré-escolar e dos ensinos básico e secundário, bem como dos respectivos agrupamentos. Diário da República. Lisboa, Ministério da Educação, n. 102, 1998. Série II, p. 1998(2)-1998(25).

PORTUGAL. Despacho $\mathrm{n}^{\circ} 12.591$, de 16 de junho de 2006. Regulamenta a escola a tempo inteiro e define as Atividades de Enriquecimento Curricular (AEC), nos domínios desportivo, artístico, científico, tecnológico e das tecnologias da informação, por meio das atividades de apoio ao estudo, ensino de inglês, ensino de outras línguas estrangeiras, atividade física e desportiva, ensino de música e outras. Diário da República. Lisboa, Ministério da Educação, n. 115, 2006. Série II, p. 8783.

PORTUGAL. Lei de Bases do Sistema Educativo (LBSE) n 46/86, de 14 de outubro de 1986. Assembleia da República decreta, nos termos da Constituição, a Lei de Bases do Sistema Educativo. Diário da República. Lisboa, Ministério da Educação, n. 237, 1986. Série I, p. 3067-3081.

PORTUGAL. Lei $\mathrm{n}^{\circ} 85$, de 27 de agosto de 2009. Estabelece o regime da escolaridade obrigatória para as crianças e jovens que se encontram em idade escolar e consagra a universalidade da educação pré-escolar para as crianças a partir dos 5 anos de idade. Diário da República. Lisboa, Ministério da Educação, n. 166, 2009. Série I. Disponível em: <http://www.dge.mec.pt/sites/default/files/EInfancia/documentos/ lei 85 2009.pdf> . Acesso em: 21 mar. 2018. 
SPINK, M. J. Desvendando as teorias implícitas: uma metodologia de análise das representações sociais. In: GUARESCHI, P. A.; JOVCHELOVITCH, S. Textos em Representações Sociais. 4. ed. Petrópolis: Vozes, 1995. p. 117-145. 